\title{
AN ASSESSMENT OF LABORATORY CONTAMINATION AT THE ISOTRACE RADIOCARBON FACILITY
}

\author{
D M GURFINKEL
}

Collegium Archaeometricum, c/o Department of Metallurgy and Materials Science, University of Toronto, Toronto, Ontario

Canada, M5S $1 \mathrm{~A} 4$

\begin{abstract}
An assessment of the contamination contribution of various sample preparation procedures used at the Isotrace Radiocarbon Facility, University of Toronto, is described. Samples of geologic material, millions of years old, or samples derived therefrom, were tested because these would presumably contain only dead carbon. Results showed, however, that ${ }^{14} \mathrm{C}$ contamination could be detected in several samples, complicating the contamination assessment. Best estimates of the contamination contribution from sample preparation were reported as: cracking: $<0.17 \%$ modern, acetylene synthesis: $<0.25 \%$ modern, combustion: $<0.39 \%$ modern, and handling: $<0.54 \%$ modern. These estimates were reported as upper limits because they likely represented ${ }^{14} \mathrm{C}$ derived from two sources: sample preparation and the sample itself.
\end{abstract}

\section{INTRODUCTION}

Contamination introduced during sample preparation is believed to be a major contributor to the background measured in accelerator mass spectrometry (AMS). Thus, it is important to evaluate each step in the procedure as a possible source of contamination. At the Isotrace Facility these steps include an initial chemical pretreatment such as acid-base extraction for organic samples (eg, charcoal, wood, bone collagen) or an acid leach for inorganic carbonates (eg, shell). The pretreated residues are then combusted (organic material) or hydrolyzed in acid (carbonates). The resultant carbon dioxide is next converted to acetylene which is decomposed by means of a "cracking" process to form solid carbon targets. These targets are placed in a cesium ion source from which a carbon beam is generated and analyzed by AMS. Operation of the cesium ion source and accelerator has been described by Kieser et al (1986).

This study describes efforts made in 1984 and early 1985, and briefly summarized by Beukens, Gurfinkel and Lee (1986), to quantitatively determine the extent of contamination introduced during the combustion, acetylene synthesis, and cracking processes. Chemical pretreatment while recognized as a potential source of contamination was not investigated directly in this study. There is also no discussion of the contamination contribution from the ion source and accelerator system itself, ie, "machine background," as this is described in detail elsewhere (Beukens, Lee \& Litherland, $m$ s in preparation). In this study, the machine background is assumed constant and extremely small. The major difficulty encountered was the apparent presence of ${ }^{14} \mathrm{C}$ contamination in the samples that were expected to be dead. As a result, the contamination levels measured likely represented a combination of ${ }^{14} \mathrm{C}$ originating from the sample itself and ${ }^{14} \mathrm{C}$ introduced during sample preparation.

\section{SAMPLE PREPARATION PROCEDURES}

Combustion. Combustion was achieved using a sealed combustion tube method (H Schwarcz, pers commun, 1981). Such a tube is illustrated in Fig- 


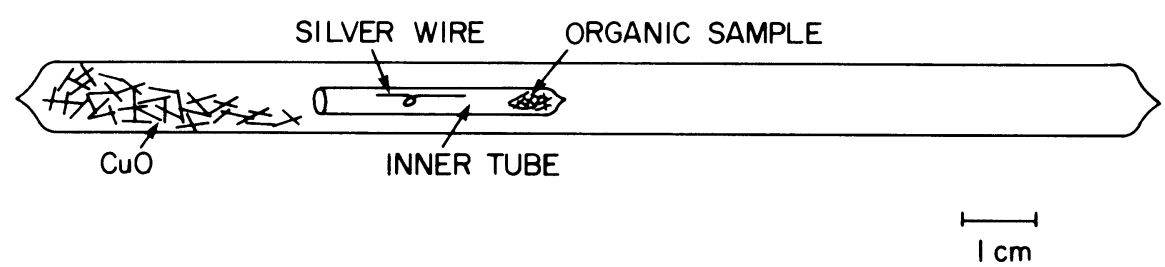

Fig 1. Sealed Vycor combustion tube

ure 1 . An organic residue, typically containing $5 \mathrm{mg}$ carbon, was placed in the Vycor inner tube shown, which was then transferred to the larger Vycor combustion tube containing cupric oxide wire (1g, Baker Analyzed Reagent). This larger tube was evacuated to 0.001 torr and sealed at the tube sealing manifold shown in Figure 2. The tube contents were mixed to ensure good contact between sample and reagents and the tube was heated at $850^{\circ} \mathrm{C}$ for two hours, then cooled down to room temperature overnight. Reduced cupric oxide in the form of cuprous oxide or copper metal was visible in the cooled tube as a pink residue. At elevated temperatures this reduced material converted any nitrogen oxides present to nitrogen which later was separated from the desired carbon dioxide gas. Silver wire (26 gauge, obtained from Sargent Welch) acted as a scrubber for sulphur and halogen compounds.

The vacuum line shown in Figure 2 was used to break the combustion

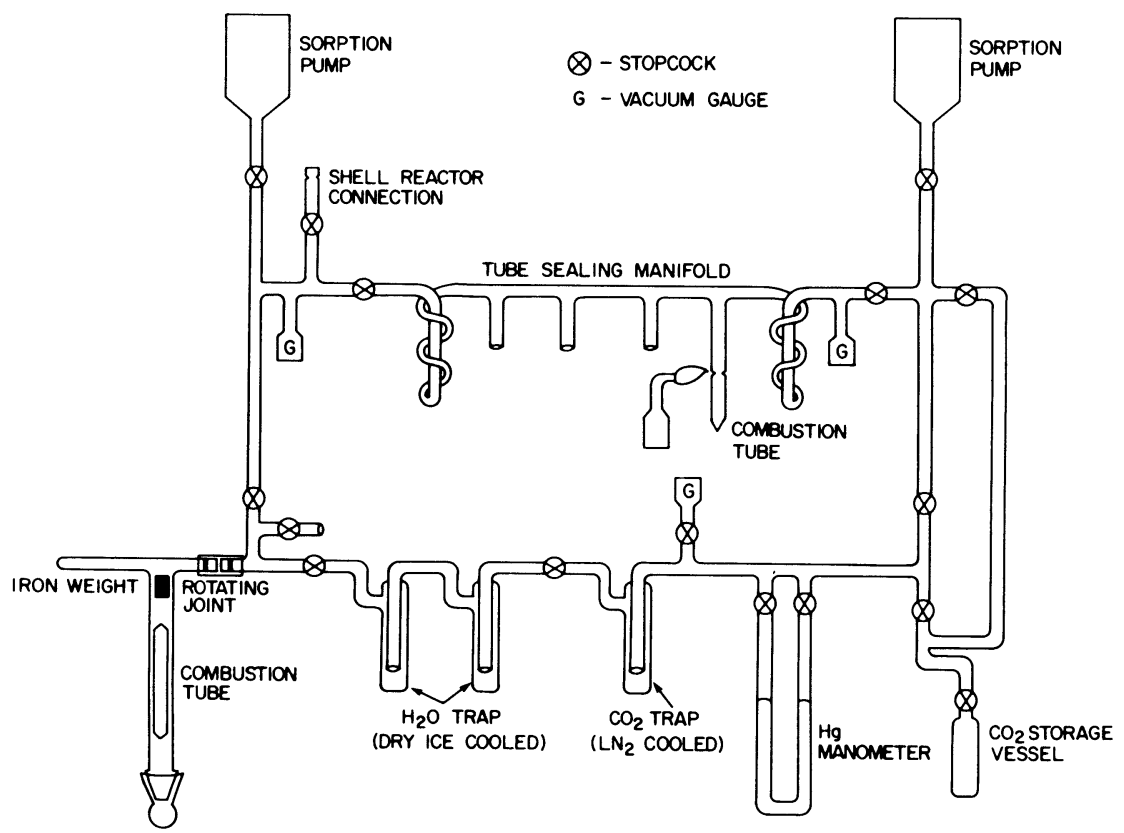

Fig 2. Carbon dioxide recovery line 
tubes and recover the carbon dioxide gas. The tube was inserted into the arm shown, which was then rotated so as to drop a weight on the tube tip, breaking it. The released carbon dioxide gas was dried over two dry ice/ alcohol traps and frozen out in a liquid nitrogen-cooled trap, while any nitrogen gas present was pumped away. The carbon dioxide was then expanded from the trap, the quantity present determined using the mercury manometer shown in the figure, and the gas then transferred to a storage vessel for subsequent acetylene synthesis. Tests with organic material of known carbon content indicated a conversion efficiency of at least $95 \%$.

Carbonate Hydrolysis. For the preparation of carbonate-containing samples, carbon dioxide was generated by acid hydrolysis in $85 \% \mathrm{H}_{3} \mathrm{PO}_{4}$ rather than from combustion (Lowdon, Wilmeth \& Blake, Jr, 1969). The gas was then dried and recovered in the line described above.

Acetylene Synthesis. The procedure described below was adapted from Polach, Gower and Fraser (1973) and was based on a two-step process for

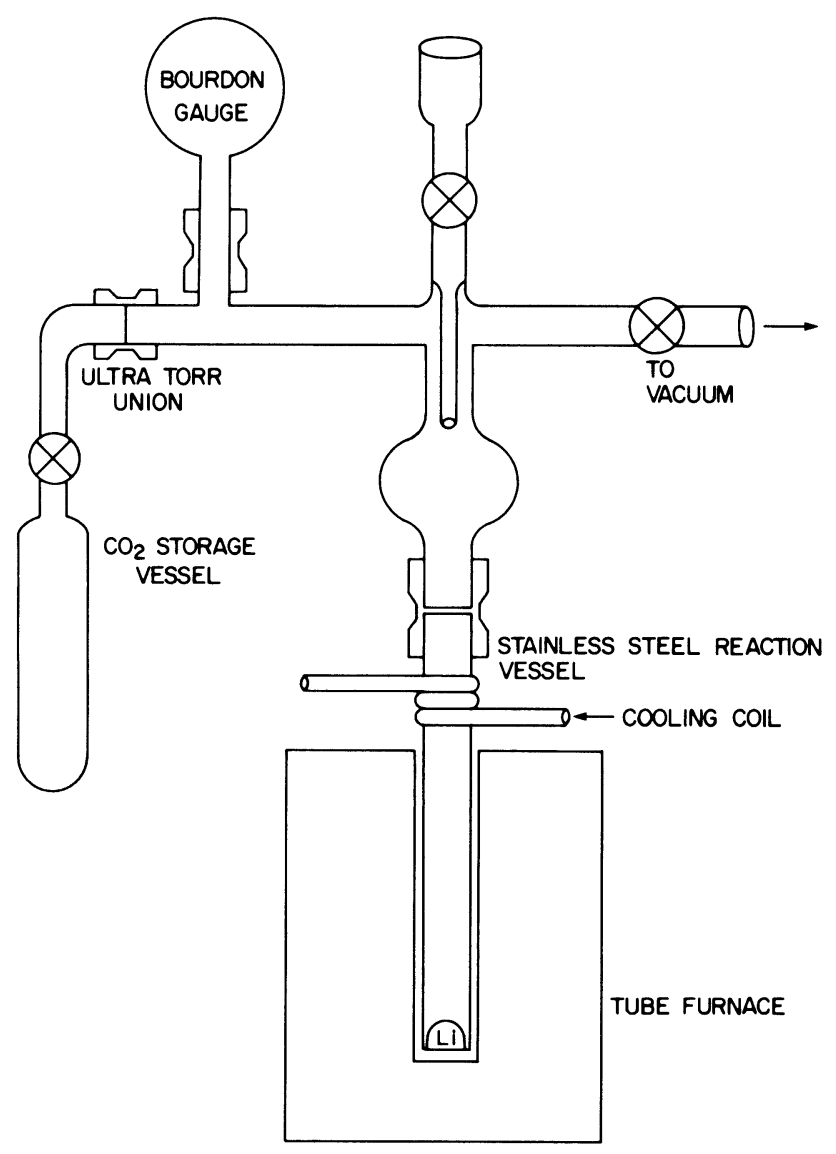

Fig 3. Lithium carbide reaction apparatus 
acetylene synthesis. Carbon dioxide was first reacted with hot lithium metal to form lithium carbide which was next reacted with water to generate acetylene.

Figure 3 shows the lithium carbide reaction apparatus. The reaction vessel was made from 304L stainless steel containing $0.03 \%$ carbon. Ca 40 to $60 \mathrm{mg}$ of lithium metal (obtained from the Lithium Corp of America) was added to this vessel, a quantity of metal representing a three to four-fold excess over stoichiometric requirements. The lithium was heated in a vacuum for 20 minutes at $600^{\circ} \mathrm{C}$ and then carbon dioxide was added. This resulted in an initial pressure rise which dropped off quickly as conversion to lithium carbide proceeded. Five minutes after addition of the gas, the reaction temperature was raised to $800^{\circ} \mathrm{C}$ for another 20 minutes to ensure complete carbide conversion. After the heating was completed, the vessel was cooled by immersion in cold water, distilled water was added to the lithium carbide and the generated acetylene was dried and collected in the line shown in Figure 4. Conversion efficiency of carbon dioxide to acetylene was found to be $80 \%$ (RP Beukens, pers commun, 1986).

Cracking. The acetylene was converted to solid carbon targets by a “cracking" process described by Beukens and Lee (1981), with one major modification. The acetylene to carbon conversion was performed in a $1 \mathrm{kv}$ AC discharge rather than in an RF discharge from a Tesla coil as originally described. Beukens and Lee also designed a more functional cracking chamber, shown in Figure 5. The carbon material was deposited simultaneously on two aluminum substrates (shown in Figure 5), the surfaces of

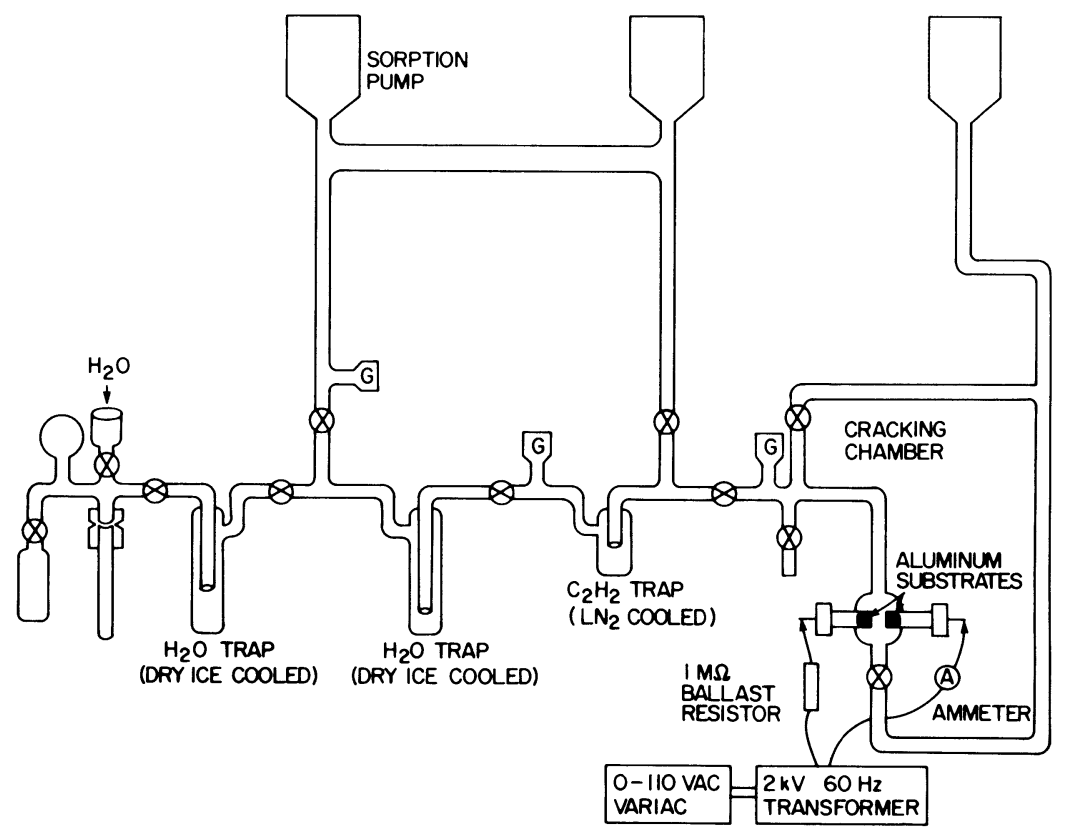

Fig 4. Acetylene recovery and cracking line 


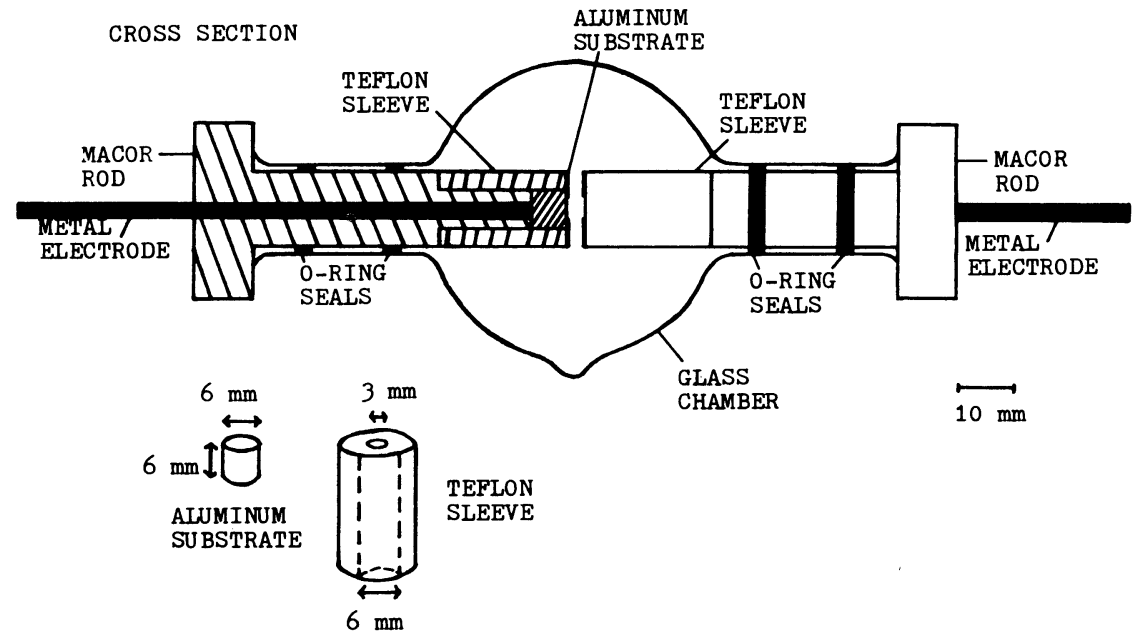

Fig 5. Cracking chamber (not shown: inlet and outlet stopcocks perpendicular to page. See Fig 4).

which were prepared by scoring with silicon carbide paper (3M \#360 or \#400) followed by ultrasonic cleaning in absolute alcohol. This roughening of the substrate surface was essential to ensure good carbon-to-aluminum adhesion under bombardment from the cesium beam in the ion source.

The cracking process proceeded as follows. Enough acetylene was added to the evacuated chamber to bring the initial pressure to 11 torr. The starting current was $0.4 \mathrm{~mA}$ and the cracking process was maintained for 12 minutes during which time the current and acetylene pressure slowly dropped. A blue-colored discharge was initially observed in the 2 to $3 \mathrm{~mm}$ gap between the aluminum surfaces but this changed to a purple color as the acetylene gas was exhausted. After 12 minutes the cracking chamber was evacuated, a second load of acetylene gas was added, and the above process was repeated. When the cracking of the second load of acetylene was complete, the carbon targets were removed from the chamber and stored in a vacuum desiccator. When enough acetylene was available, as was generally the case, a second pair of targets was produced.

Each target prepared was examined under a stereo microscope. Finegrained carbon material with good adherence to the aluminum surface was present over which a layer of carbon having a frothy, bubbly texture was usually visible. This frothy material did not perform well in the cesium ion source. For this reason it was routinely removed from the target surface by gentle scraping with a clean scalpel blade. This exposed the fine-grained carbon, ca 200 to $300 \mu \mathrm{g}$ were present, from which good carbon beams could be generated in the ion source.

Contamination Control. Several procedures were used to minimize and monitor contamination; for example, all samples were stored in polyethylene bags or glass vials. During operations, such as weighing and transfer, 
samples were handled in such a manner that only glass, metal, or dead carbon material such as plastic surfaces were contacted.

In the combustion procedure the Vycor tubes, cupric oxide, and silver wire were heated in the atmosphere at $850^{\circ} \mathrm{C}$ prior to use to ensure that any residual carbon in these materials was oxidized. Blank combustion tubes (ie, tubes containing cupric oxide and silver wire, but no sample) were run regularly and the amount of carbon dioxide generated was $0.07 \pm 0.01 \%$ of average sample size ( $5 \mathrm{mg}$ carbon).

In the acetylene synthesis process, special precautions were taken in the cleaning of the stainless steel reaction vessel. As they were shop made, the reaction vessels were quite dirty when received, having been exposed to grease and lubricants during machining. An industrial strength ultrasonic detergent (obtained from Bransonic) was used to remove these greases and lubricants. Several hot-water washes then followed to remove any traces of detergent. Next the vessels were subjected to the "pickling" process shown in Table 1 (ASM, 1964). All cleaning steps were conducted with ultrasonic agitation. The vessels were then oven-dried and stored in a vacuum desiccator. Each reaction vessel underwent a blank run (lithium only, no carbon dioxide) before being used for a sample. Acetylene was generated in these blank runs, probably originating from carbon in the stainless steel of the reaction vessel and/or from contaminants in the lithium. Acetylene blanks averaged $0.20 \pm 0.03 \%$ of typical sample size (ca $4 \mathrm{mg}$ carbon), but a vessel was considered acceptable for use if the blank was up to $0.5 \%$ of the average sample. An acceptable blank was usually obtained on the first run although occasionally a vessel would have to be run twice. Because cross-contamination effects have been reported in these vessels (Radnell \& Muller, 1980) the standard procedure was to use a reaction vessel for only one sample after which a new metal surface was exposed by reaming out the inside of the vessel and the cleaning process and blank runs were repeated.

Lithium metal was found to be very reactive. On exposure to air the metal rapidly lost its metallic sheen, changing first to a dull black (believed to be lithium nitrides and hydroxides) then to white, indicative of lithium oxides and carbonates (Mausteller, Tepper \& Rodgers, 1967). For this rea-

TABLE 1

Pickling procedure for lithium reaction vessel

\begin{tabular}{lc}
\hline Wash & Time (min) \\
\hline 1. $20 \% \mathrm{H}_{2} \mathrm{SO}_{4}$ & 10 \\
2. $20 \% \mathrm{H}_{2} \mathrm{SO}_{4}$ & 10 \\
3. Warm H $\mathrm{H}_{2} \mathrm{O}$ & 2 \\
4. $8 \% \mathrm{HNO}_{3}-3 \% \mathrm{HF}$ & 5 \\
5. Warm $\mathrm{H}_{2} \mathrm{O}$ & 2 \\
6. $20 \% \mathrm{NaOH}^{2}-6 \% \mathrm{KMnO}_{4}$ & 10 \\
7. Warm $\mathrm{H}_{2} \mathrm{O}$ & 2 \\
8. Warm $\mathrm{H}_{2} \mathrm{O}$ & 2 \\
9. $20 \% \mathrm{H}_{2} \mathrm{SO}_{4}$ & 2 \\
10. Warm $\mathrm{H}_{2} \mathrm{O}$ & 2 \\
11. $20 \% \mathrm{HNO}_{3}$ & 5 \\
12. Warm $\mathrm{H}_{2} \mathrm{O}$ & 2 \\
\hline
\end{tabular}


son the lithium, when not in use, was stored in a vacuum desiccator and when required was handled in an argon-filled glove bag. With adequately dried argon, the lithium would retain its metallic sheen while being weighed and transferred to reaction vessels.

\section{SAMPLES}

In order to study contamination effects dead samples, $i e$, samples that contained no detectable ${ }^{14} \mathrm{C}$, had to be selected. It was assumed that this could be achieved by using samples of, or derived from, geologic material millions of years old. They include:

1) Anthracite coal. This sample was obtained from the Geological Survey of Canada in the form of small black chunks no larger than a $0.4 \mathrm{~cm}$ cube. Three pretreatment procedures were applied to this sample.

a) No chemical extraction. Small portions of anthracite were broken off from randomly selected chunks and combusted directly without any pretreatment.

b) Acid-base extraction. Several grams of material were finely ground using a mortar and pestle and extracted first in base (hot $0.25 \mathrm{~N} \mathrm{NaOH}, 1$ hr) then acid (hot $2 \mathrm{~N} \mathrm{HCl}, 1 \mathrm{hr}$ ).

c) Prebaking. Several grams of material were finely ground using a mortar and pestle, heated at $600^{\circ} \mathrm{C}$ in atmosphere for $2 \mathrm{hr}$, and then stored in a glass vial.

2) Calcite. This was Precambrian (Grenville Province) crystal material collected at the Madawaska Mines in Bancroft, Ontario. The calcite crystal was initially washed in $0.1 \mathrm{~N} \mathrm{HCl}(10 \mathrm{~min})$ and then acid leached $(i e$, left overnight in a sufficient quantity of $0.2 \mathrm{~N} \mathrm{HCl}$ to hydrolyze ca $20 \%$ of the carbonate). In one treatment the calcite was coarsely ground, confining the leaching activity to outside surfaces, and in the second the calcite was finely ground, so that the leaching activity was more uniformly distributed throughout the sample.

3) Limestone. This was collected from a Paleozoic, fossiliferous limestone deposit in Prince Edward County, Ontario. It was in the form of large gray chunks which were crushed and given a routine $20 \%$ acid leach.

4) High purity graphite. This was a synthetic, zone-refined, reactor-grade graphite in rod form obtained from the Chalk River Nuclear Laboratories, Atomic Energy of Canada, Ltd, in Chalk River, Ontario. The exact origin of the carbon used in the manufacture of this graphite was unknown but was believed to be dead carbon as no appreciable difference was observed in results between this sample and natural graphite. In the laboratory the graphite was used in two forms.

a) Small cores of graphite, $3 \mathrm{~mm}$ in diameter, were drilled out of the larger rod, set in small aluminum cylinders and placed directly in the ion source.

b) A portion of the larger rod was finely ground using a mortar and pestle and then prebaked and stored in the same manner as the anthracite coal. 
5) Calcium carbonate reagent. This reagent had been stored in the laboratory for several years and the chemical supplier was unknown. It was selected for use because reagent $\mathrm{CaCO}_{3}$ is normally manufactured from limestone (Lepley, 1978). This sample was given no pretreatment.

6) Calcium carbide (technical grade $(80 \%$ obtained from $\mathrm{BDH})$ was selected for use because it was prepared by the heating of calcium oxide and coal or coke (Shine, 1978).

7) Cylinder carbon dioxide gas (obtained from Canox of Canada Ltd, Toronto, Ontario) was selected because the manufacturer indicated that it was prepared from natural gas.

\section{RESULTS AND DISCUSSION}

One of the major problems encountered in this study was the apparent presence of ${ }^{14} \mathrm{C}$ contamination in samples that were assumed dead. This was clearly indicated by the variations in results obtained in Tables 3 and 4 between different samples and for the same samples after different pretreatments. If no sample contamination were present then all similarly processed samples would have similar ages. Because of this indication of contamination, it could not be assumed that even the oldest samples were necessarily ${ }^{14} \mathrm{C}$ free. The contamination assessments for the cracking (Table 2), acetylene synthesis (Table 3), and combustion (Table 4) procedures were thus reported as upper limits.

Table 2, eg, reports the contamination level for the cracking procedure as $<0.17 \%$ modern. If it could be assumed that both the calcium carbide and high purity graphite placed directly in the ion source were dead, then the contamination from the cracking process would have been considered negligible (Beukens, Gurfinkel \& Lee, 1986). If however, one or both the samples were contaminated then the similarity between their ages would have been merely coincidental. By reporting the results as an upper limit, this possibility as well as the possibility that both samples were indeed dead have been encompassed.

Similarly in Table 3, the contamination level for acetylene synthesis was reported as $<0.25 \%$ modern based on results for finely ground calcite and in Table 4, the contamination level for the combustion procedure was reported as $<0.39 \%$ modern based on prebaked anthracite.

TABLE 2

Contamination contribution of cracking process

\begin{tabular}{lcccc}
\hline Material & $\begin{array}{c}\text { Preparation } \\
\text { processes used }\end{array}$ & $\%$ modern & $\begin{array}{c}\text { Eqv age } \\
\text { (yr BP) }\end{array}$ & $\begin{array}{c}\text { No. of } \\
\text { targets } \\
\text { measured }\end{array}$ \\
\hline $\begin{array}{l}\text { High-purity } \\
\text { graphite }\end{array}$ & $\begin{array}{c}\text { None, directly in } \\
\text { ion source } \\
\text { Cydrolysis and } \\
\text { cracking }\end{array}$ & $0.130 \pm 0.009$ & $53,600 \pm 600$ & 5 \\
\hline
\end{tabular}

Contamination contribution of cracking process: $<0.17 \%$ modern (based on results from calcium carbide sample plus 1 standard deviation) 
TABLE 3

Contamination contribution of acetylene synthesis

\begin{tabular}{|c|c|c|c|c|c|}
\hline Material & $\begin{array}{l}\text { Pretreat- } \\
\text { ment }\end{array}$ & $\begin{array}{c}\text { Preparation } \\
\text { processes used }\end{array}$ & $\%$ modern & $\begin{array}{l}\text { Eqv age } \\
(\mathrm{yr} \text { BP })\end{array}$ & $\begin{array}{c}\text { No. } \\
\text { of targets } \\
\text { measured }\end{array}$ \\
\hline Calcite & $\begin{array}{l}20 \% \text { acid } \\
\text { leach } \\
\text { finely- } \\
\text { ground } \\
\text { sample }\end{array}$ & $\begin{array}{l}\text { Acid hydroly- } \\
\text { sis, acetylene } \\
\text { synthesis, } \\
\text { and cracking }\end{array}$ & $0.237 \pm 0.015$ & $48,600 \pm 500$ & 13 \\
\hline Calcite & $\begin{array}{l}20 \% \text { acid } \\
\text { leach, } \\
\text { coarsely- } \\
\text { ground } \\
\text { sample }\end{array}$ & $"$ & $0.59 \pm 0.12$ & $41,200 \pm 1600$ & 5 \\
\hline $\begin{array}{l}\text { Lime- } \\
\text { stone }\end{array}$ & $\begin{array}{l}20 \% \text { acid } \\
\text { leach }\end{array}$ & $"$ & $0.68 \pm 0.07$ & $40,100 \pm 800$ & 1 \\
\hline $\begin{array}{l}\text { Calcium } \\
\text { carbon- } \\
\text { ate re- } \\
\text { agent }\end{array}$ & None & $"$ & $1.25 \pm 0.06$ & $35,200 \pm 400$ & 1 \\
\hline $\begin{array}{l}\text { Cyclinder } \\
\mathrm{CO}_{2}\end{array}$ & " & $\begin{array}{l}\text { Acetylene syn- } \\
\text { thesis and } \\
\text { cracking }\end{array}$ & $0.556 \pm 0.047$ & $41,700 \pm 700$ & 6 \\
\hline
\end{tabular}

Contamination contribution of acetylene synthesis: $<0.25 \%$ modern (based on results from finely ground calcite sample plus 1 standard deviation)

The differences in ages observed for the two pretreatment procedures performed on the calcite indicated the presence of a widely-distributed contaminant, which was more efficiently removed in the finely ground material because of improved acid accessibility. The origin of the contamination was unknown but may have occurred naturally, the result of penetration of modern material via a microfissure system present in the calcite crystal. That such systems exist in geologic material has been documented (RP Beukens, pers commun, 1986).

TABLE 4

Contamination contribution of combustion process

\begin{tabular}{llcccc}
\hline Material & Pretreatment & $\begin{array}{c}\text { Preparation } \\
\text { processes } \\
\text { used }\end{array}$ & \% modern & $\begin{array}{c}\text { Eqvage } \\
\text { (yr BP) }\end{array}$ & $\begin{array}{c}\text { No. of } \\
\text { targets } \\
\text { measured }\end{array}$ \\
\hline Anthracite & None & $\begin{array}{c}\text { Combus- } \\
\text { tion, acet- } \\
\text { ylene syn- } \\
\text { thesis, } \\
\text { and } \\
\text { cracking }\end{array}$ & $0.94 \pm 0.19$ & $37,490 \pm 1620$ & 8 \\
& $\begin{array}{c}\text { Acid-base } \\
\text { extraction } \\
\text { Prebaking at } \\
600^{\circ} \mathrm{C}\end{array}$ & " & $0.62 \pm 0.04$ & $40,830 \pm 510$ & 3 \\
High-purity \\
graphite
\end{tabular}

Contamination contribution of combustion process: $<0.39 \%$ modern (based on results of prebaked anthracite plus 1 standard deviation) 
The comparatively young and variable average age $(37,490 \pm 1620 \mathrm{yr} \mathrm{BP})$ obtained for the untreated anthracite material was suggestive of a heterogeneously distributed contaminant. The method of sampling used for this untreated material, randomly breaking of small portions from larger-sized chunks, made the results particularly susceptible to variability from such a contaminant. When the material was homogenized by grinding, and treated with acid and base, the average age was older and less variable than the untreated sample. The most successful treatment, however, was prebaking at $600^{\circ} \mathrm{C}$ in which presumably the contaminant was preferentially oxidized relative to the anthracite. The fact that this treatment was considerably more successful than the extractions suggested a very tightly bound contaminant.

The presence of handling contamination, ie, contamination introduced not in the processes of combustion, acetylene synthesis, or cracking specifically, but during other manipulations of the sample, was apparent in the graphite sample. The difference between the results of graphite in the ion source $(0.130 \pm 0.009 \%$ modern, Table 2) and after processing $(0.513 \pm 0.034 \%$ modern, Table 4$)$ indicated that laboratory-introduced contamination was present. Up to $0.39 \%$ modern (Table 4 ) could have originated from the combustion, acetylene synthesis, and cracking procedures itself. However, this leaves a minimum of ca $0.1 \%$ modern contamination to an upper limit of $0.54 \%$ which must have originated from other sources. As this was not ${ }^{14} \mathrm{C}$ inherently present, it must have been handling contamination.

As described in the samples section, combusted graphite underwent considerably more manipulation than the sample placed directly in the ion source. For example, combusted graphite was finely ground, a process that Gillespie and Hedges (1984) noted appears to introduce contamination. The prebaking process might have been expected to remove these contaminants, however depending on the chemical nature and binding capacity of the contaminant, removal may have been incomplete or recontamination may have occurred during subsequent storage and/or weighing and transfer of the graphite powder to combustion tubes. That contaminants can be tightly bound was illustrated with the anthracite sample. Given the highly adsorptive nature of carbon material $0.54 \%$ modern handling contamination is likely to represent a true upper limit. Less adsorptive material would presumably be less susceptible to this phenomenon.

\section{CONCLUSIONS}

Based on the above results the following conclusions can be made:

1) It cannot be assumed that any sample is "dead." If this is not recognized, misinterpretation of contamination levels could result. Note, eg, that if only the results of cylinder $\mathrm{CO}_{2}(0.556 \pm 0.047 \%$ modern $)$ and combusted graphite $(0.513 \pm 0.034 \%$ modern $)$ had been available and had been assumed dead, then this study might have concluded there was no significant contamination from the combustion procedure and ca $0.4 \%$ contamination occurred during acetylene synthesis. The use of old samples of known finite ages in the 60,000 to 70,000 years BP range to assess labora- 
tory contamination would alleviate this problem. With such samples it would be possible to determine the relative contribution of sample preparation $v s$ the sample itself in the data reported here.

2) There appears to be handling contamination which is likely to vary with sample composition. Thus, it may become necessary to determine the contamination levels for each of the material classes dated, $i e$, wood, shell, bone, charcoal, etc, as well as investigating more rigorous handling methods to minimize such contamination.

3) Based on the above data, the best estimates for the contamination contribution during sample preparation at the Isotrace Facility are:

a) cracking $<0.17 \%$ modern

b) acetylene synthesis $<0.25 \%$ modern

c) combustion $<0.39 \%$ modern

d) handling $<0.54 \%$ modern

These estimates were reported as limits because they represent contamination not just from sample preparation but possibly from the sample itself.

\section{ACKNOWLEDGMENTS}

The author wishes to acknowledge the financial support of this work by the Natural Science and Engineering Research Council, Energy, Mines, and Resources of Canada, Environment Canada, and the University of Toronto.

Thanks go to W Blake, Jr and G Wilson for donating samples used in this study and to $\mathrm{H}$ Polach for his active assistance in resolving acetylene synthesis problems during the summer of 1983.

I wish to extend my appreciation to the able staff of the Isotrace Laboratory especially R P Beukens, C Bowen, H Lee, and L Vasserman with whom I worked closely on this project. I would especially like to thank R P Beukens and A E Litherland for their valuable comments on this manuscript.

Special thanks to the members of the Collegium Archaeometricum, especially to U M Franklin for constant encouragment and guidance.

\section{REFERENCES}

ASM Committee on pickling of iron and steel, 1964, Pickling of iron and steel in Lyman, T, ed, Metals handbook, 8th ed: Metals Parks, Ohio, Am Soc Metals, p 346-356.

Beukens, R P, Gurfinkel, D M and Lee, H W, 1986, Progress at the Isotrace radiocarbon facility, in Stuiver, M and Kra, R S, eds, Internatl ${ }^{14} \mathrm{C}$ conf, 12 th, Proc: Radiocarbon, v 28 , no. 2A, p 229-236.

Beukens, R P and Lee, H W, 1981, The production of small carbon samples by RF dissociation of acetylene, in Kutschera, W, ed, Symposium on accelerator mass spectrometry, 2nd, Proc: Argonne Natl Lab, p 416-425.

Gillespie, R and Hedges, R E M, 1984, Laboratory contamination in radiocarbon accelerator mass spectrometry: Nuclear Instruments \& Methods Phys Research, Sec B, v 233, no. 2, p 294-296.

Kieser, W F, Beukens, R P, Kilius, L R, Lee, H W and Litherland, A E, 1986, Isotrace radiocarbon analysis: equipment and procedures: Nuclear Instruments \& Methods, v B15, p $718-721$.

Lepley, R H, 1978, Calcium compounds (calcium carbonate), in Grayson, M, ed, Encyclopedia of chemical technology, v 4, 3rd ed: New York, John Wiley and Sons, p 427-432.

Lowdon, J A, Wilmeth, R and Blake, Jr, W, 1969, Geological Survey of Canada radiocarbon dates III: Radiocarbon, v 11 , no. 1 , p 22-42.

Mausteller, J W, Tepper, F and Rodgers, S J, 1967, Alkali metal handling and systems operating techniques: New York, Gordon and Breach. 
Polach, H, Gower, J and Fraser, I, 1973, Synthesis of high purity benzene for radiocarbon dating, in Rafter, TA and Grant-Taylor, T, eds, Internatl ${ }^{14} \mathrm{C}$ conf, 8 th, Proc: Wellington, New Zealand, Royal Soc New Zealand, p B36-B49.

Radnell, C J, and Muller, A B, 1980, Memory effects in the production of benzene for radiocarbon dating, in Stuiver, $\mathrm{M}$ and Kra, R S, eds, Internatl ${ }^{14} \mathrm{C}$ conf, 10th, Proc: Radiocarbon, v 22, no. 2 , p $479-486$.

Shine, N B, 1978, Carbides (calcium carbide), in Grayson, M, ed, Encyclopedia of chemical technology, v 4, 3rd ed: New York, John Wiley and Sons, p 505-519. 